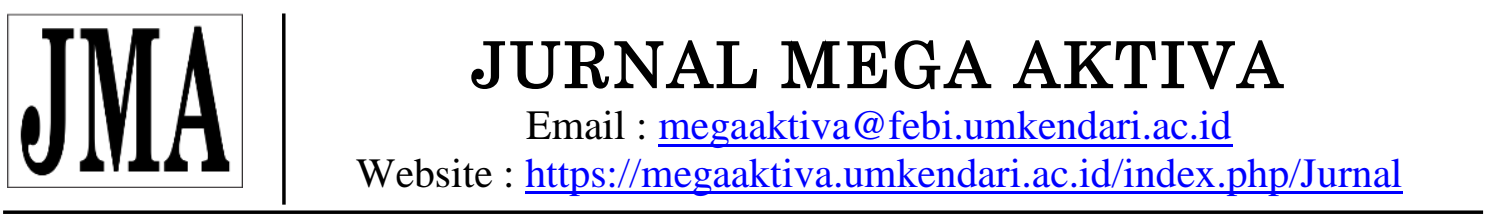

\title{
ANALISIS RANTAI PASOK CABE DI KOTA KENDARI SUPPLY CHAIN ANALYSIS OF CHILI IN KENDARY CITY
}

\author{
${ }^{1}$ Zainal Abidin \\ ${ }^{1}$ Balai Pengkajian Teknologi Pertanian Sulawesi Tenggara, Puwatu Kendari \\ Email: zainal_bptpsultra@yahoo.co.id
}

\begin{abstract}
ABSTRAK
Cabe merupakan komoditas hortikultura penting yang seringkali menjadi penyebab inflasi secara nasional. Penelitian dilakukan untuk mengetahui rantai pasok cabe di Kota Kendari. Penelitian dilakukan pad bulan Agustus-Desember 2016 menggunakan survey terstruktur terhadap 45 orang responden yang terdiri dari petani, pedagang pengumpul dan pedagang pengecer. Hasl penelitian menunjukkan bahwa struktur saluran distribusi Cabai di Kota Kendari terdiri atas (i) pedagang pengumpul; dan (ii) pedagang pengecer, dengan bentuk pasar persaingan sempurna. Pola pembentukan harga pada pedagang pengumpul mayoritas dilakukan dengan menjumlahkan biaya beli dan margin yang diharapkan, pada tingkatan pedagang pengecer mayoritas dengan pola mengikuti harga tertinggi setempat, dengan margin terbesar diterima oleh pedagang pengecer yaitu sebesar Rp. 9.666 per $\mathrm{kg}$ atau sekiatr $73 \%$ dari keseluruah margin pemasaran. Namun demikian dengan harga jual yang mencapai Rp. 42.433 per kg, petani meniukmati share harga sekita $69 \%$. Ke depan untuk menjaga agar sruktur pasar tetap pendek dan informasi harga dapat secara penuh diakses oleh seluruh pihak baik pada saluran distribusi maupun petani dan konsumen akhir dapat dilakukan melalui media konvensional namun idealnya memanfaatkan media sosial utama. Selanjutnya perlu menerapkan beberapa teknologi tepat guna pengolahan Cabai untuk pengembangan produk turunan Cabai.
\end{abstract}

Kata Kunci : Rantai Pasok, Cabe

\begin{abstract}
Chilli is an important horticultural commodity that is often increase national inflation. The research was conducted to find out the supply chain of chilli in Kendari City. The study was conducted in August - December 2016 using a structured survey of 45 respondents consist of farmers, collectors and retailers. The research result shows that the structure of the chili distribution channel in Kendari City consists of (i). collecting traders; and (ii). retailers, with a form of perfect competition market. The pattern of price formation in the majority of traders is done by summing the expected purchase and margin costs, at the level of the majority of retailers with the pattern of following the highest local prices, with the largest margin being accepted by retailers in the amount of IDR. 9,666 per $\mathrm{kg}$ or approximately 73\% of the overall marketing margin. However, the selling price reaches Rp. 42,433 per kg, farmers get more share of price around $69 \%$. For the next to keep the market structure and price information can be fully accessed by all parties both in the distribution channel and farmers and end consumers can be done through conventional media but ideally utilizing major social media. Furthermore, it is necessary to apply several appropriate technologies for processing chili for the development of chili products.
\end{abstract}

Key Words : Supply Chain, Chili 


\section{PENDAHULUAN}

Pangan merupakan salah satu kebutuhan dasar masyarakat, permintaan atas komoditas pangan terutama pangan penting (strategis) cenderung mengalami peningkatan dari waktu ke waktu, peningkatan ini relative paralel dengan peningkatan jumlah penduduk, bahkan kini perubahan cita rasa dan selera masayarakat juga ikut mempengaruhi konsumsi pangan penting.Peningkatan permintaan terhadap pangan penting tidak akan menjadi persoalan jika ketersediaan-nya (penawaran) mencukupi. Banyak wilayah di Indonesia yang menyandarkan ketersediaan pangan penting pada wilayah lainnya di Indonesia atau bahkan mengimpornya dari luar negeri.

Cabai yang merupakan komdoitas hortikultura yang memeiliki potensi pengembaagn yang besar karena permintaannya cukup tinggi dan kontinyu dan kadangkala menhjadi pemicu inflasi. Pada umumnya cabai merah digunakan sebagai bumbu masakan, bahan industri, obat-obatan, dan zat pewarna (Hutabarat \& Rahmanto 2002; Istiyana, 2013).

Pada umumnya untuk menyalurkan produk sampai ke tangan konsumen, produsen memerlukan perantara pemasaran. Saluran pemasaran adalah suatujalan yangdiikuti dalam mengalihkan pemilikan secara langsung atau tidak langsung atas suatu produk dan produk akan berpindah tempat dari produsen kepada konsumen akhir atau pemakai industri. Saluran pemasaran tersebut ada yang panjang ada pula yang pendek. Lebih lanjut disebutkan bahwa terdapat empat tingkatan saluran pemasaran yaitu (1) saluran tingkat nol (zero-level channel), (2) Saluran tingkat satu (one-level channel),(3) Saluran tingkat dua (two level channel) dan (4) Saluran tingkat banyak (multy-level channel) (Clindiff \& Still (1998): Gitosudarmo (1994) dalam Istiyana, 2013).

Calkin dan Wang (1984) efisiensi pemasaran terdiri dari efisiensi teknis dan efisiensi ekonomi. Efisiensi teknis dalam kegiatan pemasaran berkaitan dengan efektifitas yang berhubungan dengan aspek fisik dalamkegiatan pemasaran, sedangkan efisiensi ekonomi berkaitan dengan efektifitas dalam kegiatan fungsi pemasaran dilihat dari segi keuntungan yang masing-masing.

Margin pemasaran adalah selisih antara harga yang dibayarkan oleh konsumen dengan harga yang diterima produsen. Semakin panjang saluran pemasaran (makin banyak lembaga perantara pemasaran yang terlibat), maka semakin besar margin pemasaran (Daniel, 2004).

Kota kendari sebagai kota berkembang juga menunjukkan adanya dinamika pemasaran cabai merah. Hal ini karena cabai merah yang di kota Kenari bukan saja di oroduksi dari dalam wilayah Kota Kenadri, akan tetapi juga dari daerah lain bahkan ada dari antar provinsi.

\section{KAJIAN TEORITIS}

Marshal (1980) menyebutkan semakin sempurna sebuah pasar maka kecenderungan harga akan sama pada seluruh pasar yang ada. Terdapat beberapa faktor yang menyebabkan variasi harga antar wilayah (antar daerah) didalam suatu negara terutama disebabkan oleh: (i). variasi efisiensi faktor transprtasi dan distribusi; (ii). variasi dari sisi supply dan produksi; (iii). variasi dari sisi demand. Daerah yang memiliki infrastruktur wilayah yang lebih baik akan mendorong efisiensi pada biaya transportasi berbagai jenis barang utamanya yang berasal dari daerah sentra. 
Email : megaaktiva@febi.umkendari.ac.id

Website : https://megaaktiva.umkendari.ac.id/index.php/Jurnal

Konteks harga secara teoritik juga dapat dijejaki pada fungsi permintaan individu (Nicholson,2002; Samuelson dan Dordhaus, 2004), fungsi ini mengandung tiga elemen yang menentukan apa yang dapat dibeli individu, harga X dan Y dan Pendapatannya (I) dan perlu dicatat pula bahwa pilihannya juga dipengaruhi oleh preferensi barang tersebut. Sementara pada konteks barang normal (normal goods) yang jika pendapatan mengalami peningkatan dalam prakteknya orang cenderung akan membeli lebih banyak barang, berbeda dengan barang normal maka barang mewah (luxury goods) justru akan mengelami peningkatan permintaan yang lebih cepat jika pendapatan naik namun untuk barang keperluan sehari-hari (necessity) akan meningkat lebih lambat jenis barang lainnya adalah barang inferior memiliki perilaku yang juga unik, barang kategori inferior ini justru mengalami penurunan permintaan ketika pendapatan seseorang meningkat.

Harga suatu komoditi dan jumlah barang yang diperjualbelikan ditentukan oleh permintaan dan penawaran secara simultan, maka menjadi penting untuk menganalisisnya secara serentak pula. Keadaan disuatu pasar berada dalam kondisi equlibrium (keseimbangan) apabila jumlah yang ditawarkan para penjual pada suatu harga tertentu adalah sama dengan jumlah yang diminta para pembeli pada harga tersebut (Sukirno,2002).

Analisis harga memainkan peran kunci dalam pengelolaan pangan penting, Anindita (2008) mensinyalir analisis atas harga pangan merupakan metodologi yang harus dikuasai terutama dalam kaitannya dengan bagaimana pasar bergerak dan bagaimana intervensi yang dapat dilakukan. Analisis harga menjadi pintu masuk dalam upaya melakukan sejumlah kebijakan praktis khususnya dalam usaha pengendalian gejolak harga pangan penting. Selama ini upaya intervensi dilakukan ketika gejolak harga telah terjadi dan belum dapat masuk pada upaya yang lebih dalam berupa mitigasi potensi gejolak harga pangan penting.

\section{METODE PENELITIAN}

Penelitian dilaksanankan di Kota Kendari bulan Agustus -Desember 2016 menggunakan metode survey terstruktur terhadap 40 orang reponden, yang dibagi atas 3 bagian yaitu 25 orang petani cabai, 10 orang pedagang perantara/pengumpul dan 10 orang pedagang pengecer. Untuk mengetahui margin pada tiap tingkatan saluran distribusi akan dihitung dengan menggunakan formula (Sondakh et al., 2016 : Sugiarti, 2010):

$\mathrm{Mp}=\mathrm{Pr}-\mathrm{Pf}$, atau

$$
\begin{gathered}
\mathrm{MP}=\sum_{\mathrm{i}=1}^{\mathrm{n}} \mathrm{Bpi}+\sum_{\mathrm{i}=1}^{\mathrm{n}} \mathrm{Kpi} \\
\mathrm{Bpi}=\sum_{i=1}^{n} \mathrm{Bij} \\
K p i=P j i-P b i \sum_{i=1}^{n} \mathrm{Bij}
\end{gathered}
$$

Dimana:

Mp : Margin pemasaran, diukur dengan $\mathrm{Rp} / \mathrm{Kg}$

Pr : Harga di tingkat konsumen, diukur dengan $\mathrm{Rp} / \mathrm{Kg}$

Pf : Harga ditingkat produsen/distributor besar, diukru dengan $\mathrm{Rp} / \mathrm{Kg}$ 


\section{JURNAL MEGA AKTIVA}

Email : megaaktiva@febi.umkendari.ac.id

Website : https://megaaktiva.umkendari.ac.id/index.php/Jurnal

Bpi : Biaya rantai pasok ke-i, diukur dengan $\mathrm{Rp} / \mathrm{Kg}$

$\mathrm{Kpi} \quad$ : Keuntungan rantai pasok ke $\mathrm{i}$, diukur dengan $\mathrm{Rp} / \mathrm{Kg}$

$\mathrm{Pji} \quad$ : Harga jual rantai pasok ke-i, diukur dengan $\mathrm{Rp} / \mathrm{Kg}$

$\mathrm{Pbi} \quad$ : Harga beli rantai pasok ke-i, diukur dengan $\mathrm{Rp} / \mathrm{Kg}$

Bij : Biaya rantai pasok ke-i dan berbagai biaya mulai dari biaya ke-j=i, $R p / K g$

Untuk mengetahui share harga yang diterima oleh petani lokal akan dilakukan analisis share harga dengan menggunakan formula sederhana:

Dimana :

$$
\mathrm{Spl}=(\mathrm{Pf} / \mathrm{Pr}) * 100 \%
$$

Spl : share harga ditingkat petani lokal

Pf : harga ditingkat petani lokal $(\mathrm{Rp} / \mathrm{kg})$

Pr : harga ditingkat konsumen akhir $(\mathrm{Rp} / \mathrm{Kg})$

Selain itu juga akan dilakukan analisis share biaya dan keuntungan pada tingkatan rantai pasok, dengan formula masing-masing:

$$
\begin{array}{ll}
\text { Ski } & =(\mathrm{Ki}) /(\mathrm{Pr}-\mathrm{Pf}) \times 100 \% \\
\mathrm{Sbi} & =(\mathrm{Bi}) /(\mathrm{Pr}-\mathrm{Pf}) \times 100 \%
\end{array}
$$

Dimana:

Ski : share keuntungan rantai pasok ke-i

Sbi : share biaya rantai pasok ke-i

Resultante akan di ambil apabila perbandingan keuntungan dari tiap rantai pasok yang terlibat untuk tiap tingkatan tidak merata maka dapat disimpulkan rantai pasok tidak efisien,sebaliknya jika cukup merata dan logis maka dapat ditarik kesimpulan rantai pasok telah efisien (Kusuma,et all., 2013).

\section{HASIL DAN PEMBAHASAN}

Kota Kendari sebagai ibukota Provinsi Sulawesi Tenggara terletak pada bagian Selatan Khatulistiwa yakni antara $3^{\circ} 54^{\prime} 30^{\prime \prime}-4^{\circ} 3$ ' $11^{\prime \prime}$ LS dan membentang dari barat ke timur diantara $122^{\circ} 23^{\prime}-122^{\circ} 39^{\prime}$ BT dan membentang dari barat ke timur diantara $122^{\circ} 23^{\prime}-122^{\circ} 39^{\prime}$ dengan luas wilayah daratan $267,37 \mathrm{Km} 2$ dan luas wilayah laut 31.527 $\mathrm{km}^{2}$.

Berdasarkan data BPS Kota Kendari, jumlah penduduk pada tahun 2015 adalah 347.496 jiwa dengan rincian laki-laki 175.337 jiwa dan perempuan 172.159 jiwa. Keadaan penduduk menurut kelompok usia menunjukan kelompok usia< 15 tahun sebanyak 101.971 jiwa, kelompok usia 15-55 tahun sebesar 223.311 jiwa dan kelompok usia> 55 tahun adalah 22.214 jiwa. Dari sebaran kelompok usia ini terlihat bahwa kelompok usia usia produktif ( 15 - 55 tahun) merupakan kelompok usia terbanyak atau sekitar 64,26persen dari total jumlah penduduk Kota Kendari.

Produk Domoestik Regional Bruto ( PDRB ) Kota Kendari adalah Nilai tambah bruto seluruh barang dan jasa yang dihasilkan diwilayah kendari yang timbul akibat kegiatan ekonomi dalam satu priode, berdasarkan data BPS kota kendari angka PDRB Kota Kendari mulai tahun 2010 - 2015 disajikan dalam Tabel 1 
Email : megaaktiva@febi.umkendari.ac.id

Website : https://megaaktiva.umkendari.ac.id/index.php/Jurnal

Tabel 1. Produk Domestik Regional Bruto Kota Kendari Tahun 2011-2015

\begin{tabular}{ccc}
\hline Tahun & $\begin{array}{c}\text { Jumlah } \\
\text { (Juta Rupiah })\end{array}$ & $\begin{array}{c}\text { Persentase } \\
\text { pertumbuhan }\end{array}$ \\
\hline 2011 & $9.036 .001,2$ & 10,26 \\
\hline 2012 & $9.926 .251,5$ & 9,85 \\
\hline 2013 & $1.078 .797,3$ & 8,98 \\
\hline 2014 & $11.796 .868,5$ & 9,35 \\
\hline 2015 & $12.852 .518,3$ & 8,95 \\
\hline
\end{tabular}

Sumber: BPS Kota Kendari, 2016

Berdasarkan tabel diatas angka PDRB kota kendari sejak tahun 2011 sampai 2015 jumlah nilai nominl PDRB mengalami pertumbuhan, namun secara siknifikan nilai persentase dari Tahun 2011 sebesar 10,26, namun persentase pertumbuhan 2015 mengalami penurunan sebesar 8,95 tingkat pertumbuhan. Hasil ini menunjukkan peronomian Kota kendari mengalami perlambatan pertumbuhan.

\section{Karakteristik Responden}

Responden dalam survei ini berjumlah 40 responden yang terdiri atas responden konsumen akhir pangan penting, serta responden untuk rantai pasok (supply chain) pangan penting dan responden untuk regulator pangan penting.

Tabel 2. Karakteristik Responden Berdasarkan Usia, 2016

\begin{tabular}{cccccccc}
\hline No. & $\begin{array}{c}\text { Usia } \\
\text { (tahun) }\end{array}$ & \multicolumn{2}{c}{ Petani } & \multicolumn{2}{c}{ Pedagang Pengumpul } & \multicolumn{2}{c}{ Pedagang Pengecer } \\
\cline { 3 - 8 } & $\begin{array}{l}\text { Jumlah } \\
\text { (orang) }\end{array}$ & Prosentase & $\begin{array}{l}\text { Jumlah } \\
\text { (orang) }\end{array}$ & Prosentase & $\begin{array}{l}\text { Jumlah } \\
\text { (orang) }\end{array}$ & Prosentase \\
\hline 1 & $20-30$ & 5 & 20 & 1 & 10 & 2 & 20 \\
\hline 2 & $31-40$ & 7 & 28 & 5 & 50 & 3 & 30 \\
\hline 3 & $41-50$ & 8 & 32 & 2 & 20 & 4 & 40 \\
\hline 4 & $>50$ & 5 & 20 & 2 & 20 & 1 & 10 \\
\hline \multicolumn{2}{c}{ Jumlah } & 25 & 100 & 10 & 100 & 10 & 100 \\
\hline
\end{tabular}

Sumber : Analisis data rumah primer, 2016

Tabel 2 menunjukkan bahwa sebagian besar responden, baik petani, maupun pedagang termasuk dalaam kategori usia produktif. Hal ini penting karena faktor usia akan mencerminkan kematangan dalam pengambilan keputusan termasuk keputusan dalam memasarkan produk cabai yang diusahakan.

Karakteristik responden berdasarkan pendidikan dibagi dalam beberapa tingkatan yaitu: SD. SMP, SMA, D3, S2, S2 dan Tidak pernah duduk di bangku sekolah/pendidikan. Keragaan pendidikan responden pelaku pemasaran cabe di Kota Kendari disajikan pada Tabel 3. 


\section{JURNAL MEGA AKTIVA}

Email : megaaktiva@febi.umkendari.ac.id

Website : https://megaaktiva.umkendari.ac.id/index.php/Jurnal

Tabel 3. Keragaan Timgkat Pendidikan Responden Pepasaran Cabai di Kota Kenari, 2016

\begin{tabular}{ccccccc}
\hline \multirow{2}{*}{$\begin{array}{c}\text { Tingkat } \\
\text { Pendidikan }\end{array}$} & $\begin{array}{c}\text { Jumlah } \\
\text { (orang) }\end{array}$ & $\begin{array}{c}\text { Prosentase } \\
(\%)\end{array}$ & $\begin{array}{c}\text { Jumlah } \\
(\text { orang })\end{array}$ & $\begin{array}{c}\text { Prosentase } \\
(\%)\end{array}$ & $\begin{array}{c}\text { Jumlah } \\
(\text { orang) }\end{array}$ & $\begin{array}{c}\text { Prosentase } \\
(\%)\end{array}$ \\
\hline SD & 4 & 16 & 1 & 10 & 3 & 30 \\
\hline SMP & 6 & 24 & 3 & 30 & 4 & 40 \\
\hline SMA & 11 & 44 & 5 & 50 & 2 & 20 \\
\hline D3 & 2 & 8 & 0 & - & 1 & 10 \\
\hline S1 & 1 & 4 & 1 & 10 & 0 & - \\
\hline S2 & 0 & - & 0 & - & 0 & - \\
\hline Tidak ada & 1 & 4 & 0 & - & 0 & - \\
\hline Jumlah & 25 & 100 & 10 & 100 & 10 & 100 \\
\hline
\end{tabular}

Sumber : Analisis data primer, 2016

Tabel 3 menunjukkan bahwa sebagain besar responden memeiliki tingkat pendidikan antara SMP dan SMA baik pada petani, pedagang pemgumpul maupun pada pedagang eceran. Tingkat pendidikan erat kaitannya dengan kepampuan dalam mengambil keputusan berkaitan dengan produksi maupun harga yang akandi lepas kepada pelaku pasar berikutnya.

\section{Skala Usaha}

Skala usaha mencerminkan kemampuan dalam mengelola usaha berdasarkan pada penguasaan sumber daya. Khususnya pada responden petani cabai, skala usaha pada umumnya adalah < 50 are hal karena karena pengusahaan cabe memrlukan biaya pengeloaan yang cukup tinggi. Hasil wawancara menunjukkan bahwa pengusahaan cabe sekitar 50 are akan membutuhkan biaya produksi hingaa 30 - 40 juta. Meskipun demikian jika usaha tersebut berhasil (harga baik dan tanaman tidak terserang dengan penyakit) maka hasil penjualan dapat mencapai $70-80$ juta.

Selanjutnya skala usaha pedagang cabai khususnya pedagang eceran dapat dilihat dari volume penjualan yang menunjukkan bahwa sekiatr $70 \%$ hanya menjual sekitar 500 $-1.000 \mathrm{~kg}$ per bulan, hanya sekiatr $30 \%$ pedagang yang mampu menjual $>1.000 \mathrm{~kg}$ per bulan.

\section{Struktur Saluran Distribusi Cabai di Kota Kendari}

Struktur Saluran Distribusi Cabai merah di Kota Kendari terbilang pendek karena strukturnya hanya terdiri dari dua tingkatan dimulai dari: (i).pedagang pengumpul dan (ii). pedagang pengecer. Meski terbilang pendek namun struktur saluran distribusi Cabai merah dapat berkembang menjadi beberapa tingkatan terutama untuk melayani pasar 
Email : megaaktiva@febi.umkendari.ac.id

Website : https://megaaktiva.umkendari.ac.id/index.php/Jurnal

untuk kebutuhan khusus yakni permintaan pada kawasan industri di Konawe dan Konawe Utara bahkan hingga ke Kabupaten Morowali di Sulawesi Tengah.

Secara umum responden memberikan informasi bahwa Cabai merah di Kota Kendari lazim juga menjadi tempat singgah untuk kemudian dipasok kebeberapa daerah sekitar seperti kawasan industri di Konawe dan Konawe Utara, dalam posisi seperti ini maka keberadaan Pasar Induk Baruga menjadi titik penting dalam memulai menggambarkan peta jalan Cabai Merah dari petani hingga ke Konsumen akhir bagi Kota Kendari dan daerah disekitar Kota Kendari.

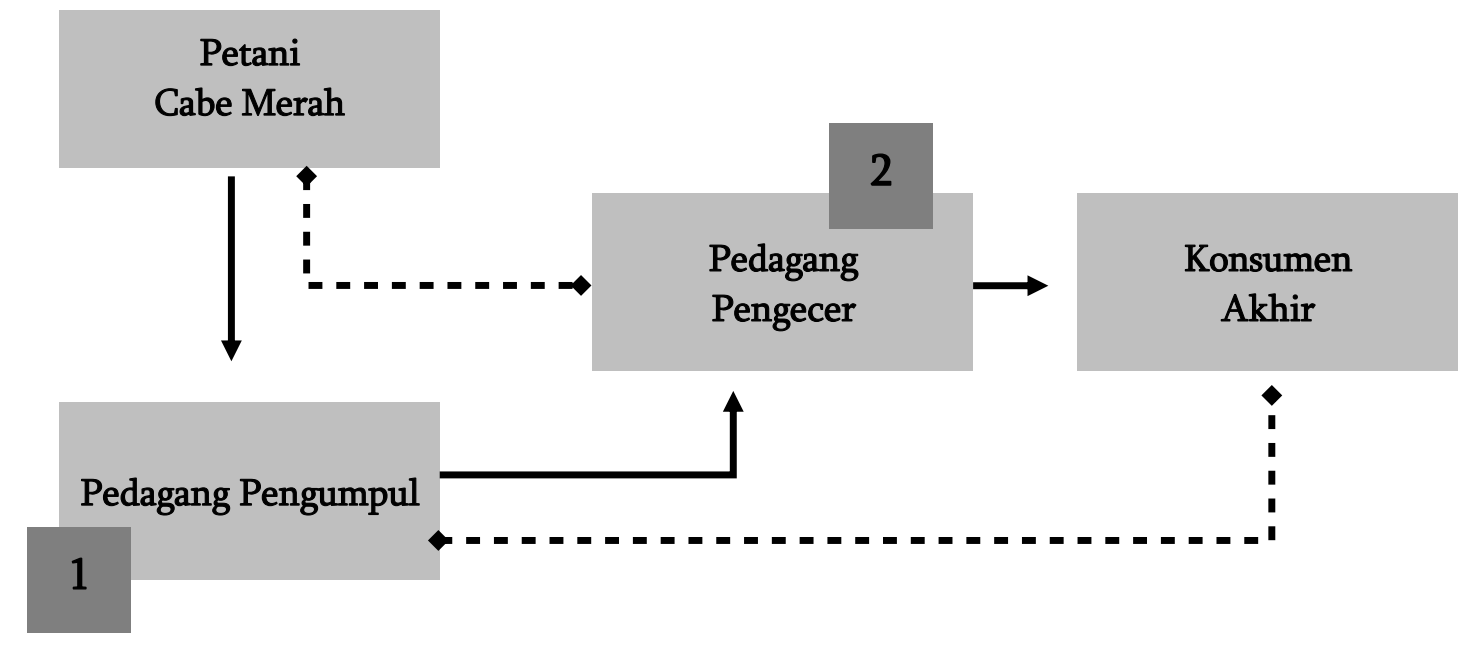

Sumber: Data Primer,2016 (diolah)

Gambar 1

Struktur Saluran Distribusi Cabai Merah di Kota Kendari

Beberapa responden menyebutkan transaksi antar tingkatan tidak berlangsung secara linier namun kadang polanya berlangsung acak, misalnya dalam beberapa situasi pedagang pengecer langsung masuk ketingkatan petani bawang merah untuk membeli hasil panennya lalu menjualnya ke konsumen akhir, pada sisi lain terdapat situasi dimana pedagang pengumpul langsung menjual Cabai merah ketingkat konsumen akhir tanpa melalui pedagang pengecer kasus ini berlangsung dimana petani Cabai merah bertindak juga selaku pedagang pengumpul.

Struktur yang pendek pada saluran distribusi Cabai merah di Kota Kendari ini juga ditopang oleh relatif dekatnya sentra produksi Cabai merah dan skala usaha petani yang relatif kecil sehingga tidak memungkinkan untuk konsolidasi pengusahaan Cabai merah dalam skala yang lebih oligopolis, pada sisi lain keberadaan pasar induk sebagai sentra sirkulasi perdagangan grosir memiliki kemampuan untuk mengurasi potensi terkonsentrasinya pelaku perdagangan Cabai merah di Kota Kendari pada sedikit pemain.

\section{Pola Terbentuknya Harga Cabai di Kota Kendari}

Mengingat relatif pendeknya saluran distribusi Cabai di Kota Kendari maka pola terbentuknya harga beli dan harga jual pada tiap-tiap tingkatan dapat diketahui. Secara rata-rata harga pada tingkatan petani terbentuk sebesar 29.250 rupiah per kilogram. 
Email : megaaktiva@febi.umkendari.ac.id

rearata harga ini merupakan harga yang diterima oleh pedagang pengumpul yang kemudian menjualnya kepada pedagang pengecer dengan harga 32.767 rupiah (rata-rata). Sebagai saluran akhir sebelum konsumen pengecer menjual dengan harga 42.433 rupiah per-kilogram kepada konsumen akhir.

Tabel 4. Pola Pembentukan Harga Cabai di Kota Kendari

\begin{tabular}{|c|c|c|c|c|c|c|}
\hline \multirow{2}{*}{ Uraian } & \multirow{2}{*}{$\begin{array}{l}\text { Petani } \\
\text { (Rp) }\end{array}$} & \multicolumn{2}{|c|}{$\begin{array}{c}\text { Pedagang } \\
\text { Pengumpul (Rp) }\end{array}$} & \multicolumn{2}{|c|}{$\begin{array}{c}\text { Pedagang } \\
\text { Pengecer (Rp) }\end{array}$} & \multirow{2}{*}{$\begin{array}{c}\text { Konsumen } \\
\text { Akhir }\end{array}$} \\
\hline & & $\mathrm{HB}$ & HJ & HB & HJ & \\
\hline Harga Per-Kg & 29.250 & 29.250 & 32.767 & 32.767 & 42.433 & \multirow{2}{*}{42.433} \\
\hline Margin Per-Kg & n.a & \multicolumn{2}{|c|}{3.517} & \multicolumn{2}{|c|}{9.666} & \\
\hline
\end{tabular}

Sumber: Data Primer Diolah, 2016

Keterangan :

$\mathrm{HB}=$ Harga Beli

HJ = Harga Jual

Berdasarkan tabel diatas tergambar margin terbesar dinikmati oleh pedagang pengecer yang secara nominal menikmati margin sebesar 9.666 rupiah sementara pada tingkatan pedagang pengumpul margin yang terbentuk sebesar 3.517 rupiah untuk tiap kilogramnya, pola ini kemudian yang ikut mendorong hubungan langsung petani dan pengecer atau antara pengumpul dan konsumen akhir, sebagaimana tergambar pada struktur saluran distribusi pada bagian sebelumnya.

Pola penentuan harga jual pada saluran distribusi Cabai di Kota Kendari tampak berbeda antara pengumpul dan pengecer, mayoritas responden pada tingkatan pengumpul menyebutkan cara mereka menentukan harga jualadalah dengan metode menambahkan antara harga beli dan margin yang mereka harapkan, kondisi sedikit berbeda pada tingkatan pengecer yang pola penentuan harga jualnya mengikuti harga tertinggi yang berlaku di pasar.

Sumber: Data Primer Diolah, 2016

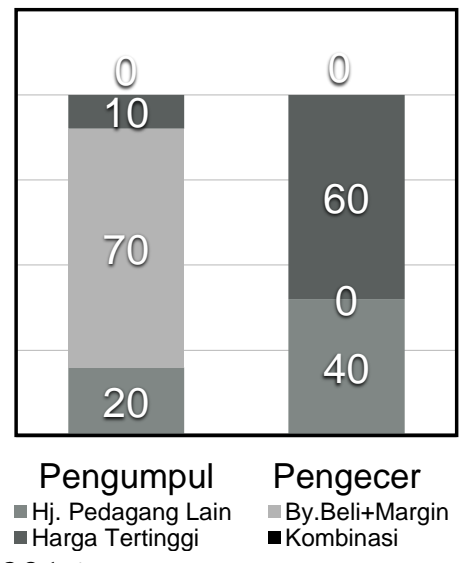

Grafik 2

Pola Penentuan Harga Jual Cabai Merah di Kota Kendari 
Email : megaaktiva@febi.umkendari.ac.id

Website : https://megaaktiva.umkendari.ac.id/index.php/Jurnal

Selain pola mayoritas diatas juga terdapat beberapa responden pada tingkatan pengumpul yang menentukan harga jual-nya dengan pola mengikuti harga tertinggi dan meniru harga jual pedagang lainnya, sementara pada tingkatan pengecer pola lainnya adalah mengikuti harga jual pedagang Cabai lainnya.

Pada tingkatan biaya, seluruh responden mengakui terdapat dua komponen biaya umum yang mereka keluarkan terkait dengan kegiatan mereka pada tingkatan saluran distribusi Cabai di Kota Kendari, yakni: (i). biaya angkut dan (ii). biaya bongkar. Komponen biaya terkandung dalam harga beli dan akhirnya harga jual pada setiap tingkatan saluran distribusi. Pada tingkatan pengumpul komponen biaya rerata 2 kali dari margin yang diperoleh pengumpul, sementara pada pengecer margin yang mereka peroleh relatif masih lebih besar dibandingkan dengan komponen biaya.

Sumber: Data Primer Diolah, 2016

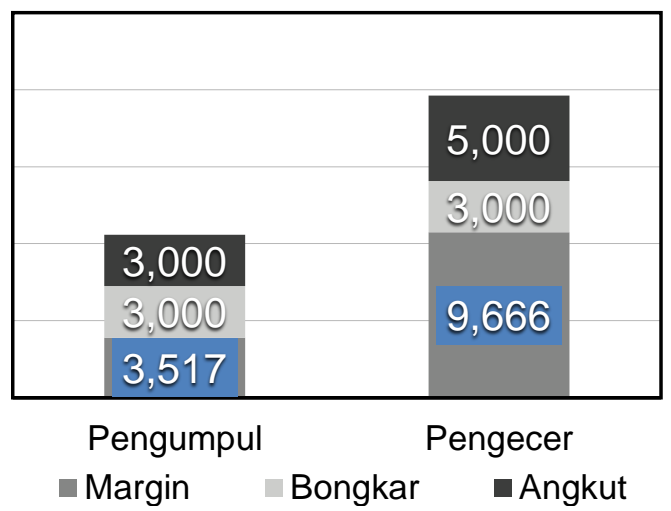

\section{Grafik 3}

Margin dan Biaya pada Saluran Distribusi Cabai

\section{KESIMPULAN}

Struktur saluran distribusi Cabai di Kota Kendari terdiri atas dua tingkat mencakup: (i). pedagang pengumpul; dan (ii). pedagang pengecer. Karakteristik pasar pada kedua tingkatan saluran distribusi adalah persaingan sempurna. Pola pembentukan harga pada pedagang pengumpul mayoritas dilakukan dengan menjumlahkan biaya beli dan margin yang diharapkan, pada tingkatan pedagang pengecer mayoritas dengan pola mengikuti harga tertinggi setempat. Margin terbesar diterima oleh pengecer yaitu sebesar Rp. 9.666 per kg. Ke depan untuk menjaga agar sruktur pasar tetap pendek dan informasi harga dapat secara penuh diakses oleh seluruh pihak baik pada saluran distribusi maupun petani dan konsumen akhir dapat dilakukan melalui media konvensional namun idealnya memanfaatkan media sosial utama. Selanjutnya perlu menerapkan beberapa teknologi tepat guna pengolahan Cabai untuk pengembangan produk turunan Cabai.

\section{DAFTAR PUSTAKA}

Agustian A., Henny. M, 2008. Pola Distribusi Komoditas Kentang Di Kabupaten Bandung, Jawa Barat. Jurnal Ekonomi Pembangunan Vol. 9 (1). Universitas

Muhammadiyah Surakarta. Surakarta. Hal. 96 - 106

Anindita, R. 2004. Pemasaran Hasil Pertanian. Papyrus. Surabaya. 


\section{JURNAL MEGA AKTIVA}

Email : megaaktiva@febi.umkendari.ac.id

Website : https://megaaktiva.umkendari.ac.id/index.php/Jurnal

Daniel, M, 2004. Pengantar Ekonomi Pertanian. PT. Bumi Aksara. Jakarta.

Edward, W, Clindiff., RichardR. Still, 1998. Dasar-Dasar Marketing Modern. Terjemahan Norman, A. P. Govoni. Liberty, Yogyakarta. Gitosudarmo,I. 1994. Manajemen Pemasaran. BPFE. Yogyakarta.

Hutabarat, B., Rahmanto, B, 2002. Dimensi Oligopsonistik Pasar Domestik Cabai Merah (Online). Pusat Penelitian dan Pengembangan Sosial Ekonomi Pertanian, Bogor. Vol 4.

Istiyanti, 2013. Efisiensi Pemasaran Cabai Merah Keritingdi Kecamatan Ngemplak Kabupaten Sleman. Jurnal Pertanian MAPETA, Vol. XII. No. 2. Universitas Veteran Jawa Timur. Surabaya. Hal $72-144$

Nicholson, W, 2002. Mikro Ekonomi Intermediate dan Aplikasinya. Edisi kedelapan. Penerbit Erlangga. Jakarta.

Samuelson, Paul A., Nordhaus, William D, 2004. Ilmu Mikro Ekonomi. Edisi Bahasa Indonesia, PT. Media Global Edukasi. Jakarta

Sondakh J., A. Wahid Rauf, Janne H.W. Rembang, Sudarti, 2016. Analisis Produksi Dan Rantai Pemasaran Jagung Di Kabupaten Minahasa Selatan Provinsi Sulawesi Utara. Jurnal Pengkajian dan Pengembangan Teknologi Pertanian, Vol. 19, No.3. Balai Besar Pengkajian dan pengembangan Teknologi Pertanian. Hal. : 213-226

Sugiarti, 2010. Analisis Pemasaran Kopi Di Kecamatan Bermani Ulu Raya Kabupaten Rejang Lebong. Jurnal Agrisep Vol 9(10). Badan penerbitan Fakultas Pertanian Universitas bengkulu. Bengkulu. Hal. 130 - 136.

Sukirno, Sadono, 2002. Teori Mikro Ekonomi. Cetakan Keempat Belas. Rajawali Press: Jakarta 